\title{
SISTEM INFORMASI GEOGRAFIS VISUALISASI MEREK DAN DESAIN INDUSTRI UMKM BERPOTENSI HKI DI KABUPATEN KUDUS
}

\author{
Suciningtyas \\ Fakultas Hukum, Program Studi Ilmu Hukum \\ Universitas Muria Kudus \\ Email: sucifhumk@yahoo.co.id \\ Andy Prasetyo Utomo \\ Fakultas Teknik, Program Studi Sistem Informasi \\ Universitas Muria Kudus \\ Email: andyutomo@gmail.com \\ Pratomo Setiaji \\ Fakultas Teknik, Program Studi Sistem Informasi \\ Universitas Muria Kudus \\ Email: pratomo.setiaji@gmail.com
}

\begin{abstract}
ABSTRAK
UMKM harus dikelola sesuai dengan kaidah bisnis termasuk dalam hal persaingan usahanya. Sifat kekeluargaan dalam masyarakat yang diterapkan dalam bisnis tidak dapat disamakan dengan bisnis milik keluarga. Teknik-teknik tertentu dalam menangani masalah perusahaan tidak selalu cocok untuk diungkap secara terbuka terhadap perusahaan lain apalagi terhadap pesaing bisnisnya. Oleh karena itu dalam bidang HKI (Hak Kekayaan Intelektual) khususnya merek dan desain industri, hal-hal tersebut juga mendapat perlindungan hukum. Penelitian ini bertujuan untuk membantu pemerintah daerah kabupaten Kudus untuk dapat lebih mudah dalam mengetahui lokasi dan sebaran UMKM yang mempunyai potensi HKI khususnya di merek dan desain industri, sebagai langkah awal untuk melakukan pembinaan kepada UMKM tentang arti pentingnya HKI. Pendekatan yang digunakan untuk pengembangan sistem dalam penelitian ini adalah dengan model prototype. Metode pengembangan sistem yang digunakan adalah OOD (Object Oriented Development) dengan tool UML (Unified Modelling Language). Hasil penelitian berupa aplikasi sistem informasi geografis berbasis web.
\end{abstract}

Kata kunci: UMKM, HKI, merek dan desain industri, sistem informasi geografis. .

\section{ABSTRACT}

SMEs should be managed in accordance with the rules of the business including its business in terms of competition. The nature of family in society that are applied in the business can not be equated with the family-owned business. Certain techniques in dealing with the company is not always suitable for openly disclosed to other companies especially against business competitors. Therefore, in the field of IPR (Intellectual Property Rights) particular brand and industrial design, these things also get legal protection. This study aims to help local governments of Kudus district to be able to more easily determine the location and distribution of SMEs(Small and medium-sized enterprises) that have the potential of IPR, especially in the brand and industrial design, as a first step to provide guidance to SMEs on the importance of IPR. The approach used for system development in this research is the prototype model. System development method used is the OOD (Object Oriented Development) with a tool UML (Unified Modeling Language). The Results of research is web-based geographic information system applications.

Keywords: SMEs, IPR, trademark and industrial design, geographic information systems.

\section{PENDAHULUAN}

Usaha Mikro Kecil dan Menengah (UMKM) di Indonesia mempunyai peranan yang sangat penting dalam membangun perekonomian bangsa. Bentuk usaha inilah yang cepat pulih dapat bertahan pada saat Indonesia dilanda krisis ekonomi pada tahun 1998 dibandingkan usaha - usaha yang berskala besar. Di Kabupaten Kudus sendiri terdapat banyak UMKM dengan jumlah tidak kurang dari 1000 UMKM. Semua UMKM tersebut tentu memiliki sejumlah Hak Kekayaan Intelektual yang perlu mendapatkan perlindungan. Namun demikian, mengingat budaya hukum masyarakat Indonesia yang bersifat 
kebersamaan, kekeluargaan dan kegotongroyongan, masih perlu dikaji lebih lanjut tentang perlindungan hukum yang di bidang HKI (Hak Kekayaan Intelektual) yang dimiliki oleh sejumlah perusahaan terutama UMKM di Kudus

UMKM adalah suatu organisasi bisnis yang harus dikelola sesuai dengan kaidah bisnis termasuk dalam hal persaingan usahanya. Sifat kekeluargaan dalam masyarakat yang diterapkan dalam bisnis tidak dapat disamakan dengan bisnis milik keluarga. Teknik-teknik tertentu dalam menangani masalah perusahaan ini tidak selalu cocok untuk diungkap secara terbuka terhadap perusahaan lain apalagi terhadap pesaing bisnisnya. Oleh karena itu dalam bidang Hak Kekayaan Intelektual, hal-hal seperti tersebut diatas juga mendapat perlindungan hukum. Namun hal tersebut tidak disadari oleh sebagian pengusaha kecil sehingga hal-hal yang mestinya dapat disimpan sebagai "nilai plus" untuk usaha justru diungkapkan kepada "teman-teman" bisnisnya yang sebenarnya adalah juga pesaing bisnisnya.

Merek adalah tanda yang berupa gambar, nama, kata, huruf- huruf, angka- angka, susunan warna, atau kombinasi dari unsur-unsur tersebut yang memiliki daya pembeda dan digunakan dalam kegiatan perdagangan barang atau jasa [1]. Sedangkan desain industri adalah suatu kreasi tentang bentuk, konfigurasi atau komposisi garis atau warna, atau garis dan warna, atau gabungan dari padanya yang berbentuk tiga atau dua dimensi yang memberikan kesan estetis dan dapat diwujudkan dalam pola tiga atau dua dimensi serta dapat dipakai untuk menghasilkan suatu produk, barang, komoditas industri atau kerajinan tangan [2]. Merek dan desain industri merupakan bagian dari HKI yang termasuk dalam kategori hak kekayaan industri.

Pemerintah Daerah Kabupaten Kudus sendiri sudah mempunyai data UMKM yang diantaranya terdiri dari data lokasi, produk yang dihasilkan, jumlah tenaga kerja, nama pemilik dan lain - lain. Meskipun begitu, pembinaan tentang pentingnya HKI bagi UMKM di Kudus masih sulit dilakukan karena belum adanya data yang berhubungan dengan potensi HKI misalnya merek dan desain industri yang dimiliki oleh UMKM di Kudus.

Penelitian ini bertujuan untuk membantu pemerintah daerah kabupaten Kudus untuk dapat lebih mudah dalam mengetahui UMKM mana saja yang mempunyai potensi HKI khususnya di merek dan desain industri. Selain itu pemerintah daerah juga dapat mengetahui sebaran lokasi UMKM berdasarkan potensi HKI. Sebaran lokasi tersebut akan disajikan dalam bentuk tampilan visual dari peta yang berbasiskan Sistem Informasi Geografis (SIG).

SIG adalah seperangkat alat yang kuat berbasis komputer yang digunakan untuk mengumpulkan, menyimpan, memanipulasi, menganalisis dan menampilkan informasi spasial yang telah direferensikan [3]. Lokasi dari setiap UMKM yang berpotensi HKI kategori merek dan desain industri akan dilakukan digitasi menggunakan alat penerima GPS (Global Positioning System) untuk mendapatkan titik lokasi garis lintang dan garis bujurnya. Berdasarkan letak garis lintang dan garis bujur tersebut nantinya setiap UMKM akan ditampilkan di peta kabupaten Kudus.

\section{METODOLOGI PENELITIAN}

Pendekatan yang digunakan untuk pengembangan sistem dalam penelitian ini adalah prototype. Pendekatan prototype digunakan untuk mempercepat implementasi beberapa bagian dari sistem selama atau sebelum fase persyaratan. Desain prototipe, dengan cepat dievaluasi oleh pelanggan / pengguna dan hasil evaluasinya digunakan untuk memperbaiki perangkat lunak yang dikembangkan [4].

Metode pengembangan sistem yang digunakan adalah OOD (Object Oriented Development).

OOD adalah metode yang membawa kita ke dekomposisi berorientasi objek. Dengan menerapkan desain berorientasi objek, kita dapat menciptakan perangkat lunak yang tangguh dengan meminimalisasi penulisan ekspresi serta mengurangi risiko yang melekat dalam pengembangan sistem perangkat lunak yang kompleks [5]. Sedangkan tools yang digunakan untuk merancang sistem informasi geografis di penelitian ini adalah UML (Unified Modelling Language). UML adalah alat untuk merinci sistem perangkat lunak yang mencakup diagram standar untuk mendefinisikan, menggambarkan dan secara visual memetakan atau memodelkan desain dan struktur sistem perangkat lunak. Diagram UML terdiri dari diagram use case, diagram kelas, diagram sekuence, diagram statechart, diagram aktivitas, diagram komponen, dan diagram deployment [6].

Tahapan yang dilakukan dalam penelitian ini ditunjukkan pada gambar 1. Penelitian dimulai dari melakukan identifikasi UMKM yang berpotensi HKI khususnya merek dan desain industri. Pada langkah pertama ini terdiri dari tiga aktifitas yaitu melakukan pencarian dan pengumpulan data UMKM di kabupaten Kudus, salah satunya dengan mengajukan permintaan data ke BPS (Badan Pusat Statistik) kabupaten Kudus. Aktifitas berikutnya adalah melakukan observasi ke lokasi UMKM berdasarkan data yang telah di dapatkan dari BPS. Di lokasi UMKM kemudian dilakukan proses digitasi untuk mengetahui titik lokasi garis lintang dan garis bujur dari setiap UMKM. Setelah sampai di lokasi UMKM dan bertemu 
dengan pemilik UMKM, selanjutnya dilakukan interview dan wawancara berkenaan dengan produk UMKM yang dihasilkan untuk mengetahui produk UMKM tersebut berpotensi HKI khususnya merek dan desain industri ataukah tidak.

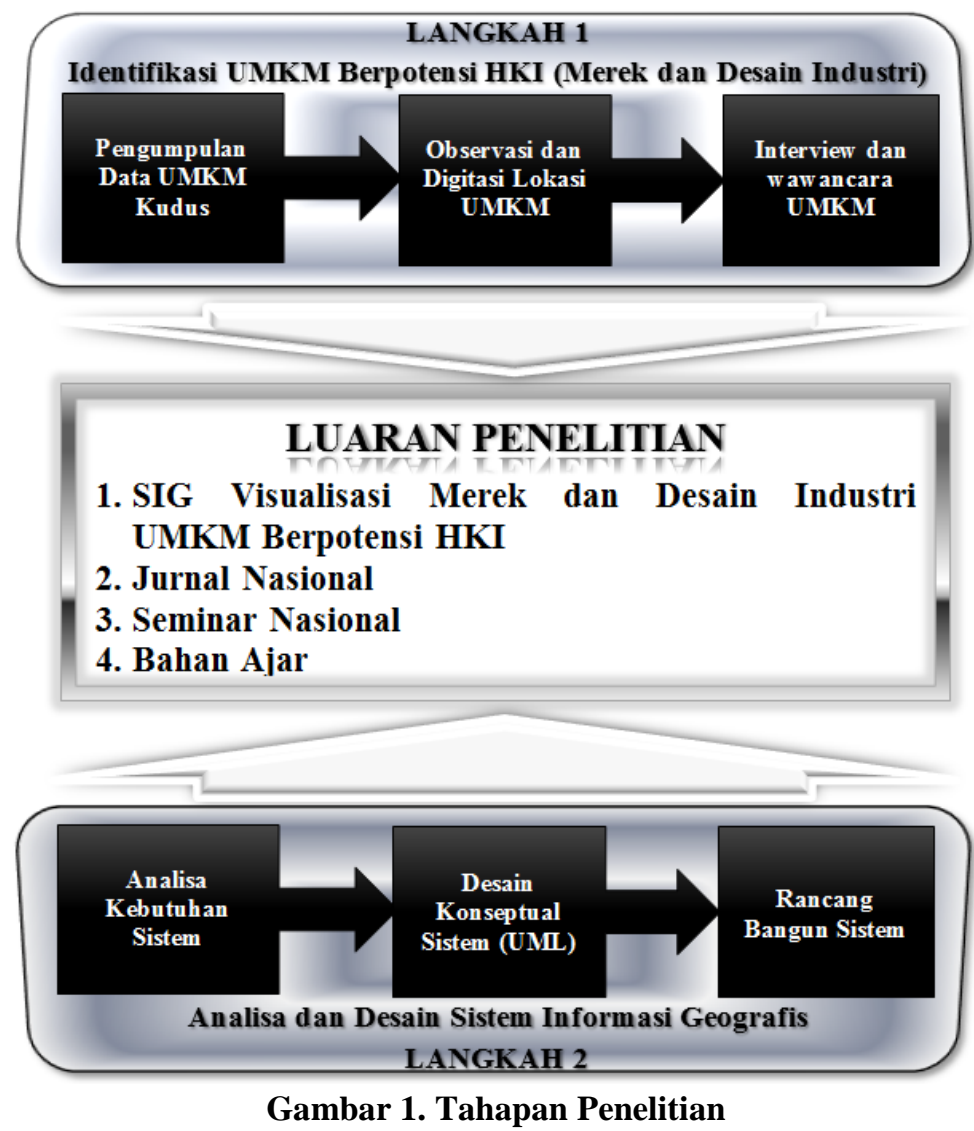

Pada langkah ke dua, berdasarkan data yang sudah diidentifikasi da didapatkan pada langkah pertama kemudian dilakukan analisa kebutuhan sistem. Dari analisa kebutuhan sistem yang dihasilkan kemudian dilakukan desain koseptual sistem yang berbentuk diagram - diagram UML. Berdasarkan desain sistem yang berbetuk diagram - diagram tersebut kemudian diimplementasikan dalam bahasa pemrograman PHP untuk membangun sebuah aplikasi berbasis WEB untuk sistem informasi geografis visualisasi merek dan desain industri di kabupaten Kudus.

\section{HASIL PENELITIAN DAN PEMBAHASAN}

Berdasarkan hasil interview dan wawancara yang dilakukan terhadap para pemilik dan pengelola UMKM, diketahui bahwa masih sangat kecilnya pemahaman dan kesadaran tentang arti pentingnya HKI di masyarakat khususnya pelaku UMKM. Banyak sekali produk - produk yang dihasilkan oleh UMKM yang berpotensi HKI khususnya merek dan desain industri, akan tetapi sangat sedikit yang berminat untuk mendaftarkan merek dan desain industri mereka tersebut agar bisa memperolah HKI. Ketidak minatan UMKM untuk mendaftarkan merek dan desain industri mereka untuk mendapatkan HKI lebih disebabkan karena kurang pengetahuan tentang HKI dan budaya hukum masyarakat Indonesia pada umumnya dan khususnya di kabupaten Kudus yang bersifat kebersamaan, kekeluargaan dan kegotongroyongan, masih perlu dikaji lebih lanjut tentang perlindungan hukum yang di bidang HKI yang dimiliki oleh sejumlah perusahaan terutama UMKM di Kudus.

Berdasarkan data digitasi lokasi dan analisa kebutuhan sistem maka kemudian dirancang konseptual sistem dalam bentuk diagram UML. Pada gambar 2 ditunjukkan diagram class dari sistem informasi geografis visualisasi merek dan desain industri di kabupaten Kudus. Diagram class tersebut menjelaskan keterhubungan antar class dan perilaku setiap class di dalam sistem. Diagram class berisikan kumpulan kelas, interface dan hubungan diantara mereka. Diagram class adalah teknik pemodelan yang umum digunakan di dalam sistem yang berbasiskan objek. Diagram tersebut memperlihatkan pandangan secara statis dari sistem [7]. 


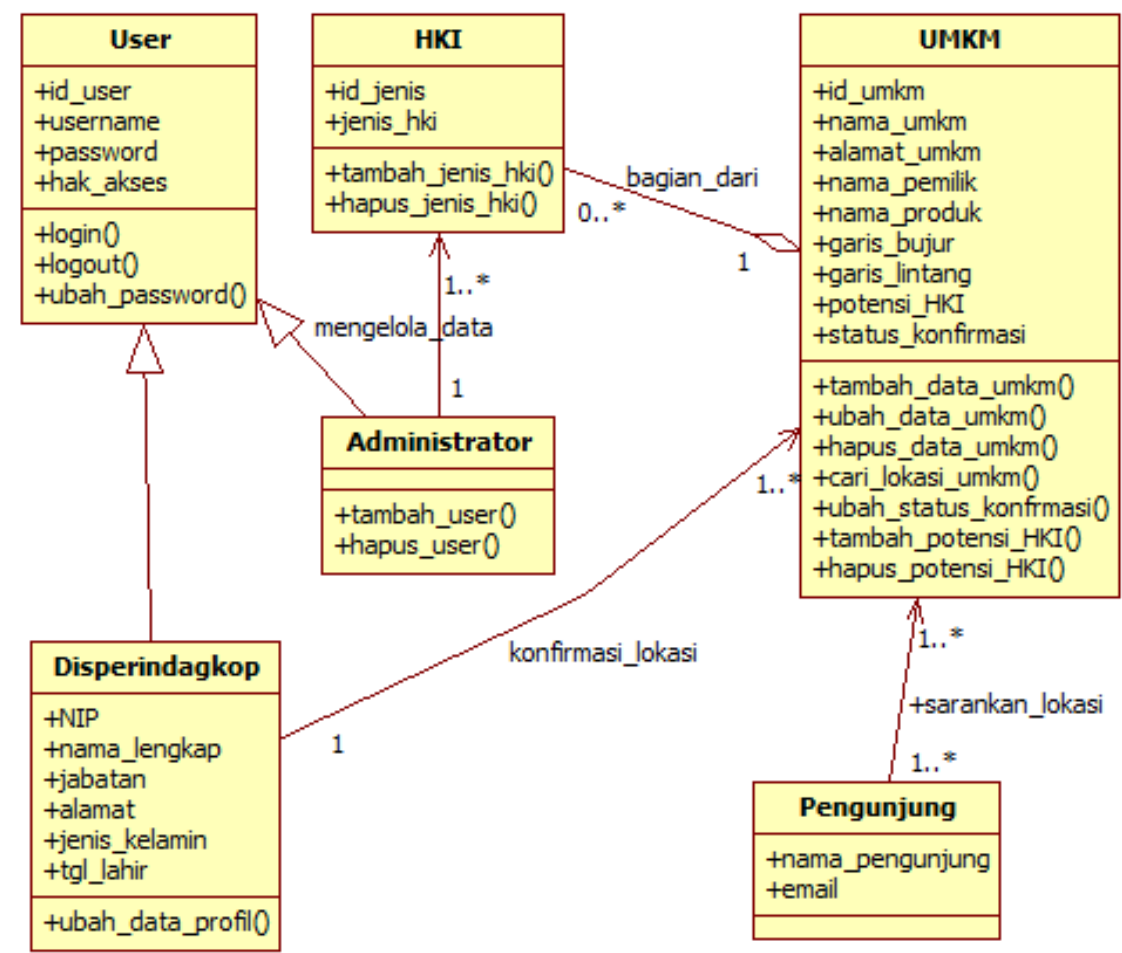

Gambar 2. Diagram Class SIG Visualisasi Merek Dan Desain Industri

Desain konseptual lain yang dihasilkan adalah diagram aktifitas, salah satunya yang ditunjukkan pada gambar 3. Gambar 3 menunjukkan diagram aktifitas dari aktor pengunjung saat melakukan aktifitas untuk menyarankan lokasi dari UMKM baru yang berpotensi HKI kepada pemerintah kabupaten Kudus. Diagram Aktifitas adalah tampilan grafis yang menjelaskan proses operasional dan hubungan sebab akibat yang digunakan di dalam setiap tahapan sistem [8].

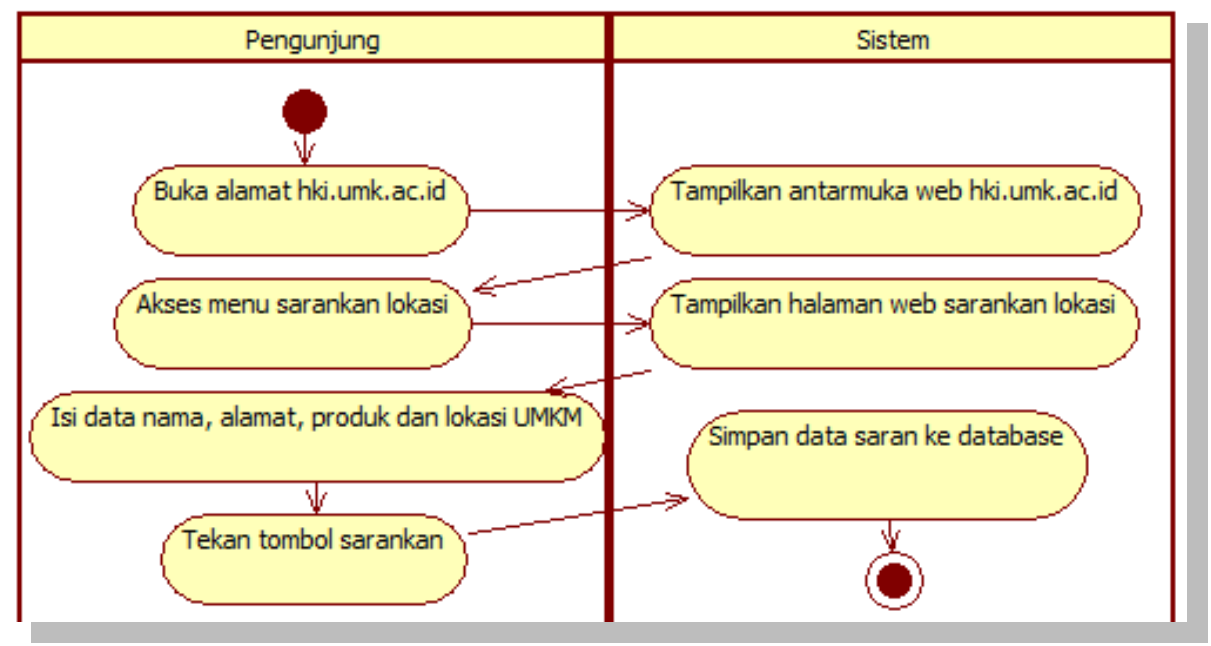

Gambar 3. Diagram Aktifitas Sarankan Lokasi

Hasil tampilan antarmuka dari sistem informasi geografis visualisasi merek dan desain industri berpotensi HKI di kabupaten Kudus ditunjukkan pada gambar 4. Simbol yang berisikan huruf D, P atau M di gambar 4 menunjukkan lokasi dari UMKM dan potensi HKI yang dipunyai. Huruf D berarti potensi HKI untuk desain industri, $\mathrm{M}$ untuk merek dan $\mathrm{P}$ untuk produk. 


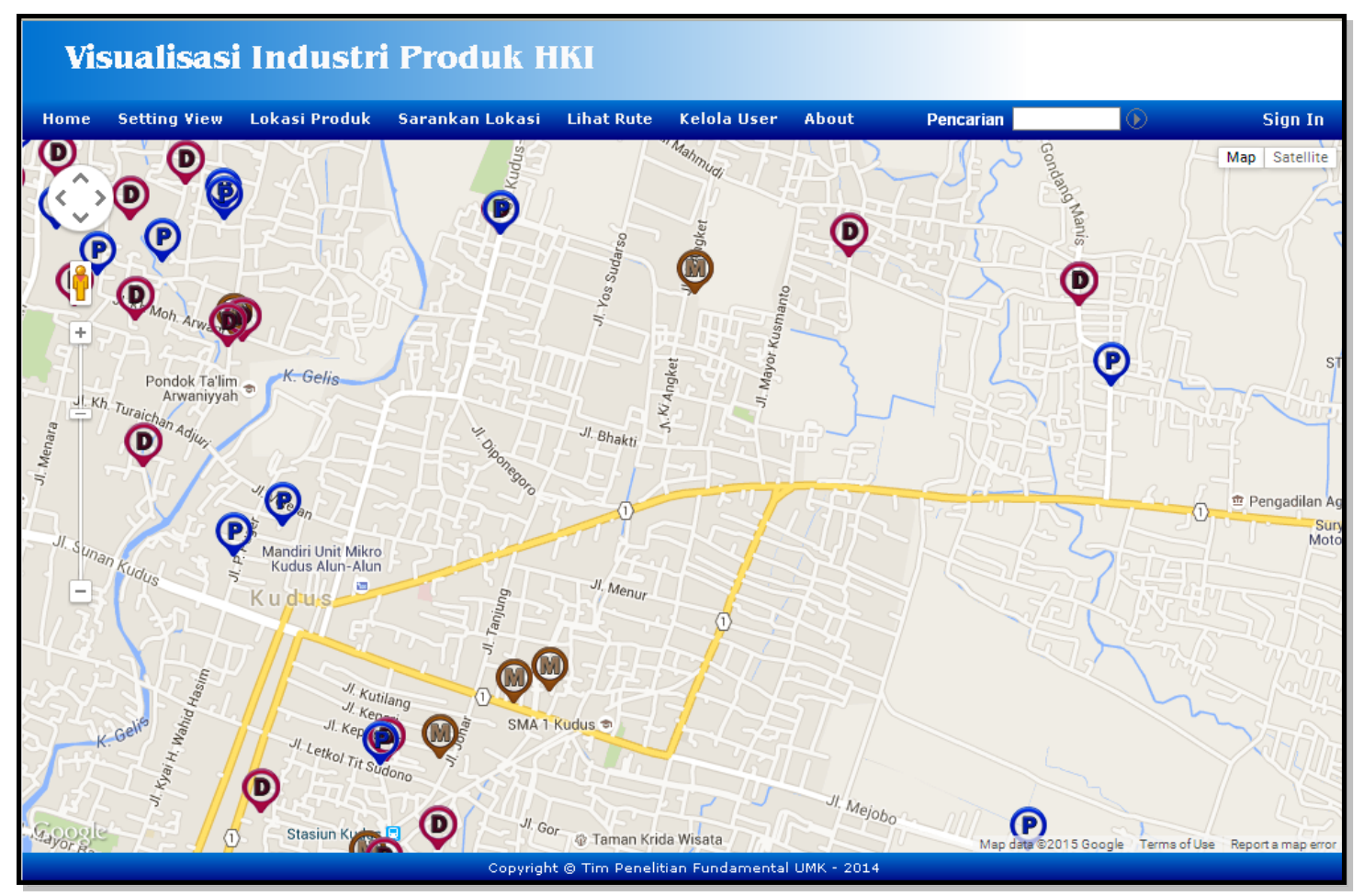

Gambar 4. Tampilan Antar Muka SIG Visualisasi Merek Dan Desain Industri

\section{KESIMPULAN}

Dari penelitian yang sudah dilakukan dapat diambil kesimpulan bahwa di kabupaten Kudus terdapat banyak UMKM yang berpotensi mendapatkan HKI khususnya merek dan desain industri. Meskipun begitu masih kurangnya pengetahuan dan pemahaman para pelaku UMKM tentang HKI menyebabkan minat untuk mendaftarkan produk mereka masih sedikit. Sistem informasi geografis visualisasi merek dan desain industri dapat digunakan oleh pemerintah kabupaten Kudus untuk membantu dalam melihat lokasi dan pengelompokkan UMKM yang berpotensi HKI, sebagai langkah awal dalam melakukan pembinaan kepada UMKM khususnya untuk mengenalkan arti pentingnya HKI khususnya di jenis merek dan desain industri.

\section{UCAPAN TERIMA KASIH}

Terima kasih kepada Direktorat Jenderal Pendidikan Tinggi, Kementerian Riset, Teknologi, dan Pendidikan Tinggi yang telah membiayai penelitian ini melalui program hibah penelitian Fundamental.

\section{DAFTAR PUSTAKA}

[1] Sekretariat Negara RI, (2001). Undang-Undang Republik Indonesia Nomor 15 Tahun 2001 Tentang Merek. Lembaran Negara Republik Indonesia Tahun 2001 Nomor 4131. Jakarta.

[2] Sekretariat Negara RI, (2000). Undang-Undang Republik Indonesia Nomor 31 Tahun 2000 Tentang Desain Industri. Lembaran Negara Republik Indonesia Tahun 2000 Nomor 243. Jakarta.

[3] Burrough, P. A., and Rachael A. McDonnell. (1998). Principles of Geographical Information Systems. New York: Oxford University Press.

[4] Tiwari, Vinay. 2010. "Some Observations On Open Source Software Development On Software Engineering Perspectives”. International Journal of Computer Science \& Information Technology (IJCSIT) 2. 6, 113-125.

[5] Booch, Grady., et al. (2007). Object-Oriented Analysis and Design with Applications. Pearson Education, Inc, USA.

[6] Lee, Sunguk. 2012. "Unified Modeling Language (UML) for Database Systems and Computer Applications". International Journal of Database Theory and Application 5. 1, 157-164. 
[7] Mallick, Bipsha., and Das, Nilanjan. 2013. "An Approach to Extended Class Diagram Model of UML for Object Oriented Software Design:, International Journal of Innovative Technology \& Adaptive Management (IJITAM) 1. 2.

[8] Kaewchinporn, Chinnapat,. and Limpiyakorn, Yachai. 2013. "Enhancement of Action Description Language for UML Activity Diagram Review”, International Journal of Software Engineering and Its Applications 7. $2,255-271$ 